\title{
Characteristics and Functional Properties of collagen extracted from Nile tilapia (Oreochromis niloticus) skin
}

Hussein Abdelaal*, Hani M.A, Mohamed, Sanaa Salah, and Reem Elhosany

Food Science Department, Faculty of Agriculture, Minia University, Minia, Egypt

* Correspondence:reem.elhusseini@mu.edu.eg; Tel:+20862342601; Fax: +20862342601

\section{Article information}

Received: 5 September 2020

Revised: 8 November 2020

Accepted: 12 December 2020

Key words

Collagen

Nile tilapia

Amino acid

Solubility

\begin{abstract}
Tilapia skin might be used as a new source of collagen, therefore collagen obtained from Nile tilapia skin can be utilized as food product because of its good functional properties. Two extraction methods were applied to obtain acidsoluble collagen (ASC) and pepsin-soluble collagen (PSC) from Nile tilapia skin. In this study, collagen was characterized in terms of FT-IR Spectrum, amino acid analysis, SDS-PAGE and Thermal denaturation temperatures (Td). Also, some major functional properties including solubility, oil and water absorption, emulsifying activity, stability, foaming ability, foam stability, and gelation properties were determined. The results showed that the yields of ASC and PSC were $4.30 \%$ and $1.84 \%$ (on a wet weight basis), respectively. Amino acid composition indicated that the imino acid content of ASC and PSC were found to be 172.10 and 164.18 residues per 1000 residues, respectively. The FTIR Spectrum confirmed that the presence of a triple-helical structure characteristic of ASC and PSC. SDS-PAGE results indicated that ASC and PSC were type I collagen. The denaturation temperature of ASC and PSC were $26^{\circ} \mathrm{C}$ and $25^{\circ} \mathrm{C}$ respectively. The solubility of ASC and PSC were highly solubilized in the $\mathrm{pH}$ range of $2-3$. ASC and PSC had good water and oil absorption capacity. Gelation studies revealed that ASC and PSC have good gelation properties. Consequently, Nile tilapia skin could be used as a good source of collagen in the food industries.
\end{abstract}

\section{Introduction}

Collagen is a main protein in all animal tissues, which comprises about $30 \%$ of total protein. It is found in bones, tendons, ligaments, eye lenses, skin, and corneas. More than 29 different of collagen from various animals have been identified. In addition, each type of collagen has a specific molecular structure and amino acid sequence [1]. The production of collagen in the body decreased through a bad diet and age. While collagen injections are not a preference for most people, so the subsequent best alternative to obtain collagen is through diet. Consequently, pure collagen has been mixed in many food products [2].

Using Acid extraction and pepsin to extract the collagen was a common method [3]. Collagen is mainly obtained from mammalian skin, such as pig and cow skin. However, because of mouth -and foot disease, mad cow disease, in addition, religious barriers. Therefore, the Collagen of fish waste has received increasing attention [4]. Fish processing manufacturing produces every year a huge amount of fish waste that represents about $25 \%$ of the total fish production. Generally, the waste mainly consists of scales, bones, skin and fins, which represent around $70 \%$ of fish Coppola et al., 2020 [5].

Tilapia is of great importance in the aquaculture sector. It is one of the commercially produced species. Tilapia skin is a waste that contains approximately $27.8 \%$ collagen so it can be used for the extraction of collagen Zeng et al., 2009 [6]. According to [7] In Egypt, production of tilapia comprised $61.44 \%$ of the total fish production. Hence the use of fish skin as new source of collagen turns low economic value raw material into a food industries [8].

Collagen has been generally applied in cosmetics; medicine and food due to its good functional properties. These include foaming ability, solubility, emulsification and oil absorption capacity [2]. Also, the high imino acid content affects the functional properties which are thermal stability and solubility of collagen [9]. Consequently, the high imino acid of collagen has broader applications in food manufacturing.

As far as we know, little information is found in the literature regarding the functional properties of collagen [10]. Consequently, it is required to evaluate the functional properties of collagen extracted from fish skin, for applying the collagens in bread, cakes, drinks, ice cream and other food application. Consequently, this study aimed to extract ASC and PSC from Nile tilapia skin. Also, the characterization and function properties of collagen were investigated to use it in food industries; the process can also find high value-added processing of waste using this new approach.

\section{Materials and Methods}




\subsection{Fish skin preparation}

Life Nile tilapia purchased from fishery market in El-Minia governorate then transported in the icebox to the Food Science Laboratory Faculty of Agriculture Minia University. The average weight and length of the fish were $478.6 \pm 33.84 \mathrm{~g}$ and $26.75 \pm 2.47 \mathrm{~cm}$, respectively. Fish samples were washed with tap water. Tilapia skins were obtained manually and cut into small pieces $(0.5 \times 0.5 \mathrm{~cm})$ then washed with cold distilled water, packed in a polyethylene bag and frozen at $-20^{\circ} \mathrm{C}$ until use.

\subsection{Extraction of acid-soluble collagen (ASC)}

The collagen has been prepared using the methods of [11] and [12]. All preparations were carried out at the temperature not higher than $7{ }^{\circ} \mathrm{C}$. The skins were stirred in $0.1 \mathrm{M} \mathrm{NaOH}$ at a ratio of $1: 8(\mathrm{w} / \mathrm{v})$ for 24 hours to elimination non-collagen compounds then the solution was changed every eight hrs. The skins were washed with distilled water until a neutral $\mathrm{pH}$ of 7 was achieved. The skin was defatted with 10 volumes of $10 \%$ butyl alcohol for $48 \mathrm{hrs}$. The alcohol solution was changed every eight hours. The defatted skins were washed with cold water and collagen was extracted by acetic acid solution, as 'acid-soluble collagen (ASC)'.

\subsection{Extraction of Pepsin- Soluble Collagen (PSC)}

Undissolved matter from acid-soluble collagen was further treated with $0.5 \mathrm{M}$ acetic acid containing $1 \%$ pepsin $(\mathrm{w} / \mathrm{w})$ at a ratio of $1: 10(\mathrm{w} / \mathrm{v})$ for 2 days at $4{ }^{\circ} \mathrm{C}$ according to the method of [13]. The obtained Collagen was called pepsin soluble collagen (PSC). Both ASC and PSC were used for analysis.

$$
\text { Yield of collagen }=\frac{\text { Weight of collagen }(g)}{\text { Weight of skin (g) }} \times 100 \%
$$

\subsection{Characterization of the extracted collagen}

\subsubsection{Amino Acid Analysis}

Collagen samples were first hydrolyzed in $6 \mathrm{~N} \mathrm{HCl}$ at $110^{\circ} \mathrm{C}$ for $24 \mathrm{hr}$. and the hydrolysates were analyzed by HPLC an amino acid analyzer [14].

\subsubsection{Fourier Transform Infrared Spectroscopy (FTIR)}

All spectra were obtained using an FTIR (Omnic spectra) spectroscopy [15].

\subsubsection{Sodium Dodecyl Sulfate Polyacrylamide Gel Electrophoresis (SDS-PAGE)}

SDS-PAGE was performed according to the methods of [16].

\subsubsection{Evaluation of collagen denaturation temperature}

The denaturation of collagen in solution was performed according to a method described by [17], [18]. A Brookfield viscometer beaker was filled with $0.1 \%(\mathrm{~m} / \mathrm{v})$ collagen solution in $0.1 \mathrm{M}$ acetic acid. Collagen solution viscosities were measured at a temperature from $10^{\circ} \mathrm{C}$ up to $50^{\circ} \mathrm{C}$. Fractional viscosities were computed for each temperature. The fraction change was calculated from the viscosity measurement obtained with the below equation. Where $\mathrm{C}$ is the collagen concentration $(\mathrm{mg} / \mathrm{mL}), \varepsilon 1$ is the viscosity at $10^{\circ} \mathrm{C}, \varepsilon 2$ is the viscosity at measured temperature

Fraction change $=[(\varepsilon 2 / \mathrm{C})-(\varepsilon 3 / \mathrm{C})] /[(\varepsilon 1 / \mathrm{C})-(\varepsilon 1 / \mathrm{C})-(\varepsilon 3 / \mathrm{C})]$ The denaturation temperature was the temperature at which the fractional viscosity value was 0.5 .

\subsection{Determination of functional properties}

\subsubsection{Effect of $\mathrm{pH}$ range (1-10) on solubility:}

Evaluation the effect of $\mathrm{pH}$ range (1-10) on the solubility of collagen according to the method of [3], [19]

\subsubsection{Effect of $\mathrm{NaCl}$ on solubility:}

The effect of $\mathrm{NaCl}$ on the solubility of collagen was determined according to the method described by [3] at different concentrations $(0,2,4,6$ and $8 \%)$ of $\mathrm{NaCl}$ and the protein content in the supernatants was evaluated by the method of [19].

\subsubsection{Water Absorption Capacity of Collagen (WAC)}

WAC was evaluated using the method of [20]. A certain quality $(\mathrm{M})$ of collagens and a certain volume $\left(\mathrm{V}_{0}\right)$ of distilled water mixed in the vortex mixer $30 \mathrm{~s}$, standing 30 $\min$ at $25^{\circ} \mathrm{C}$, then $5000 \mathrm{r} / \mathrm{min}$ centrifuge $30 \mathrm{~min}$, the supernatant volume was recorded (Vt) Water absorption was calculated as:

Water absorption capacity $(\mathrm{ml} / \mathrm{g})=\frac{V_{0}-V_{t}}{M}$

\subsubsection{Oil Absorption Capacity of Collagen (OAC)}

OAC was measured using the method of [21]. A certain quality (M) of collagens and a certain volume (V0) of oil mixed in the vortex mixer $30 \mathrm{~s}$, standing $30 \mathrm{~min}$ at $25^{\circ} \mathrm{C}$ then centrifuge $5000 \mathrm{r} / \mathrm{min}$ for $30 \mathrm{~min}$. The supernatant was measured (Vt) Oil absorption was calculated as:

Oil absorption capacity $(\mathrm{ml} / \mathrm{g})=\frac{\mathrm{V}_{0}-\mathrm{V}_{\mathrm{t}}}{\mathrm{M}}$

\subsubsection{Determination of Emulsifying Properties:}

Emulsifying activity (EA) was determined according to the method of [21], [10] and the volume of the emulsified mixture was recorded.

$\mathrm{EA}(\%)=\mathrm{v}_{1} / \mathrm{v}_{0} \times 100 \%$

Wherev $_{0}$ is the total volume of the mixture and $v_{1}$ is the volume of emulsified mixture;

Emulsion stability (ES) was calculated according to [22].

ES $(\%)=\frac{\text { High of emulsified layer after heating }}{\text { Height of emulsified layer before heating }} \times 100$

\subsubsection{Evaluation of foaming characteristics:}


Foam ability (FA) and foam stability (FS) of collagen solutions were determined, as described by [23].

\subsubsection{Gelation properties:}

Gelation properties were investigated using the method described by [24], with a slight modification at various concentrations $1-4 \%$ of collagens. The least gelation concentration was measured as the concentration when the sample from the inverted test tube did not slip or fall.

\subsection{Statistical Analysis:}

Data were analyzed with the General Linear Model program using SAS (25). Mean values were compared by Duncan's.

\section{Results and discussion}

\subsection{Yield of extracted Nile tilapia skin collagen}

The yields of ASC and PSC from Nile tilapia skin were 4.30 and $1.84 \%$ (based on the wet weight), respectively (Table 1). The yield of ASC is higher than PSC. This may be due to that collagen was incomplete solubilization in $0.5 \mathrm{M}$ acetic acid extraction through the acid-soluble method. So, when the residue was extracted by using the pepsin method, PSC was wholly solubilized. This result was in agreement with the yields of PSC and ASC of silver catfish skin (2.27\%and 4.27\%)reported by (26).On the other hand, the difference in collagen yield maybe because of the differences in preparation methods and different fish species. Yao et al., 2012 (27). In the present study, the enzyme extraction used the residual from acid extraction which was low content of collagen as compared to the raw materials. [28] reported that the yield of ASC was higher than the PSC of squid fish skin. On the other hand, [3] reported that the pepsin digestion cleaved at the telopeptide region without totally breaking the structure of collagen's triple helix, which contributed to the lower yield of PSC.

Table 1 Yield of extracted collagen of ASC and PSC of skin Nile tilapia.

\begin{tabular}{cc}
\hline Samples & Yield (\%) \\
\hline $\begin{array}{c}\text { Acid soluble collagen } \\
\text { (ASC) }\end{array}$ & 4.30 \\
$\begin{array}{c}\text { Pepsin soluble } \\
\text { collagen(PSC) }\end{array}$ & 1.84 \\
\hline
\end{tabular}

\subsection{Amino acid compositions:}

The ASC and PSC showed similar amino acid profiles with slight variations in (Table 2). It was maybe due to the elimination of some portion of telopeptides hydrolyzed by the pepsin [29]. Collagen has the highest content of glycine [30]. It was 218.3 and 226 residues $/ 1,000$ residues in ASC and PSC, respectively. This result is lower than the Nile Tilapia (Oreochromis niloticus) skin [30], the skin of Nile tilapia [31] and the Red Snapper skin [32]. Similarly, the glycine contents of channel catfish skin for ASC and PSC were 239and 233 residues/1,000 residues [33], furthermore, there are high contents of proline, alanine, glutamic acid, and hydroxyproline. Generally, there was no tryptophan in collagen [34] while tyrosine, histidine, cysteine and Isoleucine were very low, this is in agreement with [30] and [32].

The imino acid content (hydroxyproline and proline) of ASC and PSC was found to be 172.1 and 164.1 residues per 1000 residues, respectively. They are similar to surf smelt skin (172 residues/1000 residues) according to [35] and higher than the codfish skin (154residues per1000 residues) [36], and lower than the ASC and PSC from the pufferfish (329 and 334 residues/1000 residues) [34]. Furthermore, mammalian collagen, such as pig (220residues per 1000 residues) was higher imino acid content than fish collagen $\mathrm{Wu}$ et al., 2016 [37]. [38] Showed that the thermal stability of collagen increases through imino acid content. Additionally, imino acid content is the most important used for determining the thermal stability of collagen triple helix.

Table 2 Amino acid composition of ASC and PSC from the skin of Nile tilapia skin (residues/1000 residues)

\begin{tabular}{ccc}
\hline Amino acid & $\begin{array}{c}\text { Acid soluble collagen } \\
\text { (ASC) }\end{array}$ & $\begin{array}{c}\text { Pepsin soluble } \\
\text { collagen(PSC) }\end{array}$ \\
\hline Glutamic acid & 61.2 & 58 \\
Aspartic acid & 41.5 & 44 \\
Serine & 48 & 38.71 \\
Glycine & 218.3 & 226 \\
Histidine & 5.10 & 4.2 \\
Arginine & 63.5 & 62 \\
Threonine & 41 & 37 \\
Alanine & 140.1 & 180 \\
Proline & 93.4 & 89.38 \\
Tyrosine & 21.7 & 23 \\
Valine & 33.37 & 29 \\
Methionine & 21.2 & 18.3 \\
Cysteine & 0.73 & 0.8 \\
Isoleucine & 16.1 & 18 \\
Hydroxyproline & 78.7 & 74.8 \\
Leucine & 21.3 & 17 \\
Phenylalanine & 48.3 & 45 \\
Lysine & 46 & 34.81 \\
Imino acids & 172.10 & 164.18 \\
\hline
\end{tabular}

\subsection{Fourier Transform Infrared Spectrophotometer (FTIR):}

Both ASC and PSC presented characteristic peaks of amide $\mathrm{A}$ and $\mathrm{B}$ in addition to amide I, II, III (Figures 1and 2). Amide A band positions of ASC and PSC were obtained at wave-number 3427.69 and $3324.48 \mathrm{~cm}$ 1respectively which similar to amide $\mathrm{A}$ in red snapper fish collagen, it was obtained at wave number $3417.86 \mathrm{~cm}$ 1[32]. This band is related to $\mathrm{N}-\mathrm{H}$ stretching vibrations included in the hydrogen bonds of the peptide chains and 
usually occurs in the range of 3400-3440 cm-1 and when hydrogen bonds were introduced there are become lower to around $3300 \mathrm{~cm}^{-1}$ [37]. On the other hand, the Amide $\mathrm{B}$ band positions of ASC and PSC were detected at 2926.00 and $2928.27 \mathrm{~cm}-1$, respectively. The amide B band is related with an asymmetrical stretch of $\mathrm{CH} 2$ [13]. Amide B band of samples similar to Nile tilapia [31], silver carp [29], and channel catfish [39]. The main peaks in the spectra of ASC and PSC from Nile tilapia skin were similar to puffer fish collagen [34]. The amide I band of ASC and PSC was detected at 1647.52 and $1653.02 \mathrm{~cm}-1$, respectively. The amide $\mathrm{I}$ band is generally associated with the carbonyl group $(\mathrm{C}=\mathrm{O})$ stretching vibration, it normally occurred in the range $1600-1700 \mathrm{~cm}-1$ and is an indication of the secondary structure of the peptide [32]. Amide II of ASC and PSC was detected at 1541.02 and $1541.94 \mathrm{~cm}-1$, respectively. Amide II band was related to $\mathrm{CN}$ stretching and $\mathrm{NH}$ bending vibration [37].

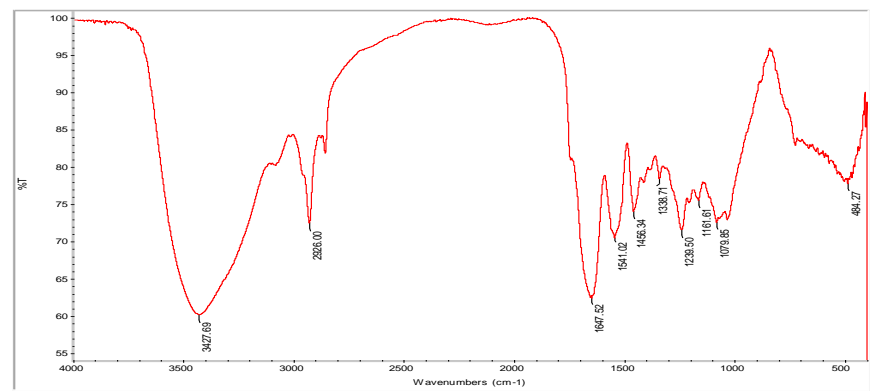

Figure 1: Fourier transform infrared spectra (FTIR) of acidsoluble collagen (ASC)

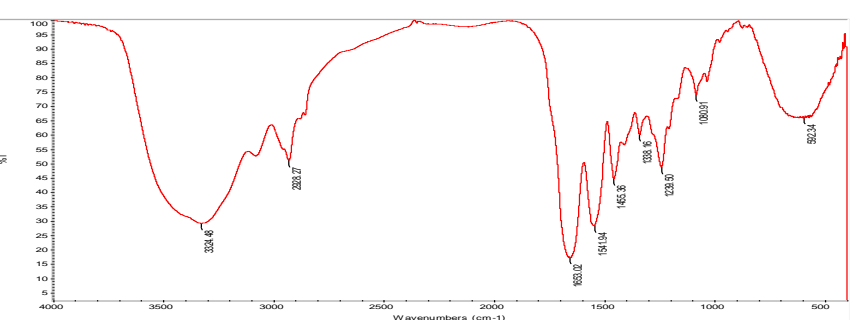

Figure 2: Fourier transform infrared spectra (FTIR) of pepsin-soluble collagen (PSC)

Also, the amide III band (1220-1320 cm-1) was related to the mixture of the stretching vibration between $\mathrm{C}-\mathrm{N}$ and the $\mathrm{N}-\mathrm{H}$ bending vibration. The amide III band of ASC and PSC was found at wave-number $1239.50 \mathrm{~cm}-1$ [34]. The amide I, amide II, amide III bands wavenumbers are exactly associated with the collagen formation, Therefore, from these results, it was confirmed that the presence of a triple-helical structure-property of Nile tilapia in both the ASC and PSC.

\subsection{SDS - PAGE analysis}

ASC and PSC contain two $\alpha$ chains ( $\alpha 1$ and $\alpha 2)$ showed in (Figure 3). The molecular weight of $\alpha 1$ and $\alpha 2$ of PSC was $146 \mathrm{kDa}$ and $86 \mathrm{kDa}$, respectively. On the other hand, the molecular weights of $\alpha 1$ and $\alpha 2$ chains of ASC were 135 and $102 \mathrm{kDa}$, respectively. The patterns were similar to the molecular masses of $\alpha 1$ and $\alpha 2$ therefrom loach fish skin were $127 \mathrm{kDa}$ and $115 \mathrm{kDa}$, respectively [13]. High molecular weight components, containing $\gamma$ and $\beta$ chains, were also higher in ASC than PSC (Fig 3). Because of the cross-link containing telopeptides was broken by pepsin, and then the $\beta$-chain is turned to two achains. This pattern was proven by earlier research conducted by [40].

[41] reported that collagens consist of intra molecular and inter cross-linked components of $\gamma$ and $\beta$. Also [42] showed that more amounts of molecular cross-linked components and $\beta$ chains were detected in Tilapia waste collagen. These results indicated that ASC and PSC may be described as type I collagen. Chen et al., 2019[43] reported that the ASC contained more dimers and trimers compared to PSC This result is in agreement with skin collagens from pufferfish by [34] and loach fish [13].

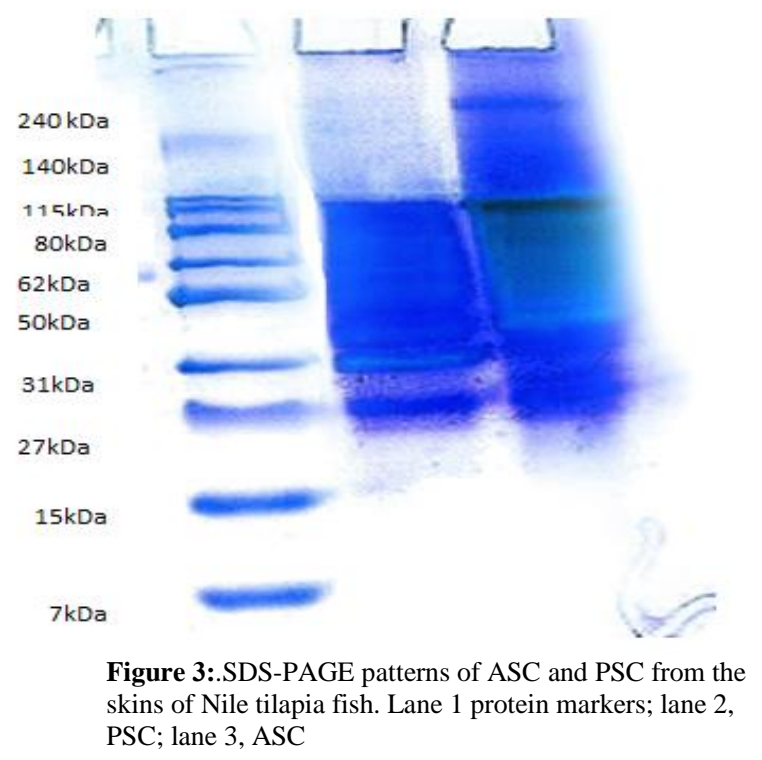

\subsection{Denaturation temperature $(\mathrm{Td})$}

Td of ASC Nile tilapia was $26^{\circ} \mathrm{C}$ and PSC was $25^{\circ} \mathrm{C}$ in (Figure 4), the difference Td of ASC and PSC due to the hydrolysis action of the enzyme. These values are similar to collagens of red stingray skin which recorded at $\mathrm{Td}=$ 23.82 ${ }^{\circ} \mathrm{C}$ ASC and $24.46{ }^{\circ} \mathrm{C}$ PSC Chen et al., 2019[43]. The Td of miluy croaker swim bladders for $\mathrm{ASC}=24.7^{\circ} \mathrm{C}$ and $\mathrm{PSC}=26.7^{\circ} \mathrm{C}$ ) [44]. The $\mathrm{Td}$ of tiger puffer skin for $\mathrm{ASC}=28{ }^{\circ} \mathrm{C}$ and $\mathrm{PSC}=25.5{ }^{\circ} \mathrm{C}$ [45] respectively. But lower than the $\mathrm{Td}$ of Nile tilapia skin $\left(35.2{ }^{\circ} \mathrm{C}, \mathrm{ASC}\right)$ [31].The $\mathrm{Td}$ of river puffer skin for $\mathrm{ASC}=29.5^{\circ} \mathrm{C}, \mathrm{PSC}=$ $27.5{ }^{\circ} \mathrm{C}$ [45].Also, according to $\mathrm{Li}$ et al. 2013 [46], the collagen of land animal had a higher denaturation temperature than that fish collagen due to its higher amino acid content.

Chen et al., 2019 [43] showed that the hydrogen bond in the collagen molecule was destroyed when the temperature rises therefore the triple helix structure dissociates then converts into random coil. Thus, the viscosity of collagen decreases. On the other hand, Nile tilapia collagens had a higher denaturation temperature 
than cold water fish collagen such as Spanish mackerel ( $\mathrm{Td}$ of $\mathrm{ASC}=15.12^{\circ} \mathrm{C}$ and $\mathrm{Td}$ of $\mathrm{PSC}=14.66^{\circ} \mathrm{C}$ ) li et al., 2013 [46].

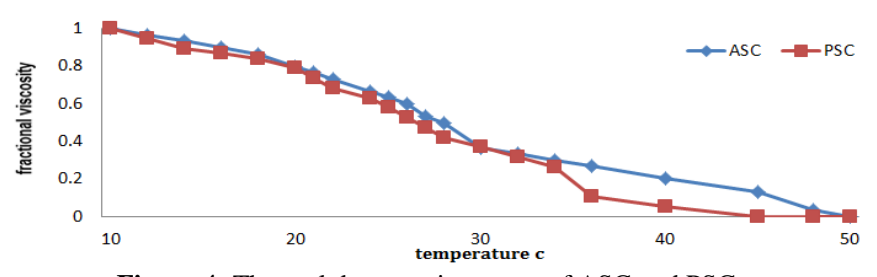

Figure 4: Thermal denaturation curve of ASC and PSC from Nile tilapia skin, as shown by changes in fractional viscosity

\subsection{Determination of functional properties}

\subsubsection{Effect of $\mathrm{pH}$ and $\mathrm{NaCl}$ concentration on collagen solubility}

\subsubsection{Effect of $\mathrm{pH}$ on collagen solubility}

The highest solubility of ASC and PSC was at $\mathrm{pH} 3$ and $\mathrm{pH} 2.5$ respectively (Figure 5). Both the collagens indicated the highest solubility in the acidic region $\mathrm{pH}$ (13). At above $\mathrm{pH} 3$, the solubility started to decrease. A similar result was shown for Pufferfish skin collagen [47] and ASC from silver catfish [12]. Also, [34] revealed that the solubility of ASC and PSC of pufferfish skin achieved the maximum at $\mathrm{pH} 3$ and then decreased above this $\mathrm{pH}$.

[15] reported that most of the solubility of collagen increased in acidic conditions. Furthermore, the least solubility was detected at $\mathrm{pH}$ 6. This likely due to the isoelectric point ( $\mathrm{pI}$ ) of the proteins, as after getting to $\mathrm{pI}$, the total net charge of proteins becomes zero leading to precipitation [3]. Also, PSC presented better solubility than ASC; this was due to a slight variation in the structure, composition and properties of trimer [48].

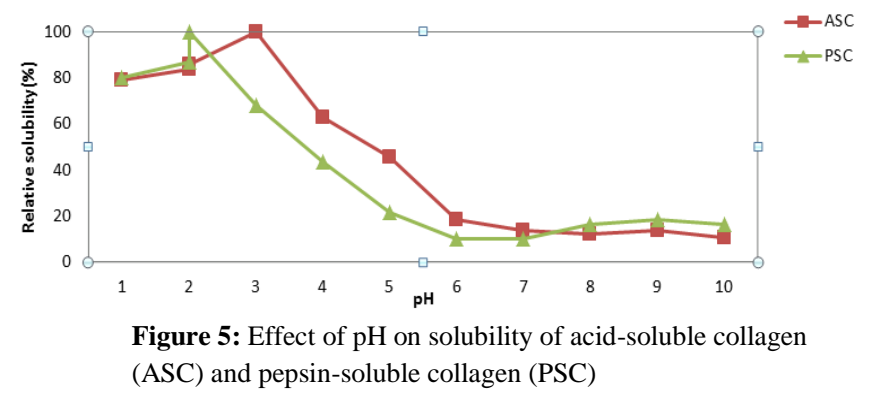

\subsubsection{Effect of salt concentration on collagen solubility}

Both ASC and PSC presented similar solubility at various $\mathrm{NaCl}$ concentrations $(0-10 \%)$ in (Figure 6). The sharp decrease when the solubility was above $2 \% \mathrm{NaCl}$ concentration for both ASC and PSC with $\mathrm{NaCl}$ concentration was increasing because the hydrophobic interactions increased. Also, the competition for the ionic salts with water increased leading to protein precipitation [47]. These are in agreement with what was found by [5] who reported that the solubility of collagens from the Brown stripe red snapper fish skin was decreased at $3 \%$ $\mathrm{NaCl}$ or above.

Also, the ASC and PSC showed the best solubility at low $\mathrm{NaCl}$ concentration $(0,1$ and $2 \%)$, because the salt ions bind weakly to charged groups on the protein surfaces [49]. This result was similar to the solubility of the tilapia skin Zeng et al., 2009[6], and Pufferfish skin [47].

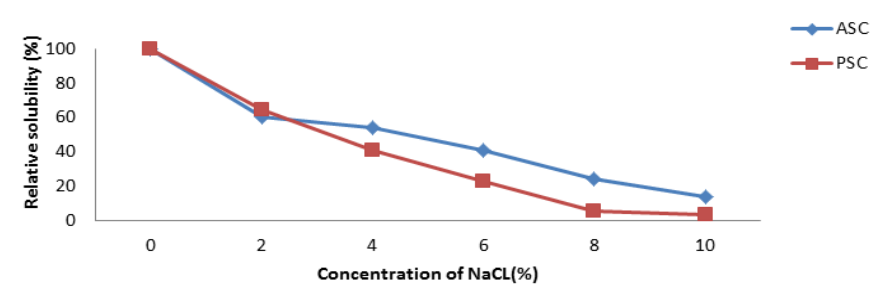

Figure 5: Relative solubility of acid soluble collagen (ASC) and pepsin soluble collagen (PSC) at various $\mathrm{NaCl}$ concentrations.

\subsubsection{Water Absorption Capacity (WAC) and Oil Absorption Capacity (OAC) of Collagen}

WAC and OAC of collagens from Nile tilapia skin were shown in Table 3. ASC was significantly higher in WAC than PSC. The WAC of ASC was $23.924 \mathrm{ml} / \mathrm{g}$, but the PSC was $22.72 \mathrm{ml} / \mathrm{g}$ ) ( $\mathrm{P}<0.05)$, which may be due to its higher ratio of hydrophilic areas [50]. This result is similar to PSC and ASC red stingray skin. there were 28.48 and20.76 mL/g, respectively Chen et al., 2019[43]. The OAC of ASC was higher than PSC, $26.72 \mathrm{ml} / \mathrm{g}$ and $24.51 \mathrm{ml} / \mathrm{g}$ respectively. The OAC of a protein is associated with non-polar amino acids. Accordingly, the OAC values denoted that ASC has non-polar amino acids higher than PSC. These results are similar to the collagen of red stingray skin Chen et al., 2019[43].

Table 3 :Water and oil absorption capacities of skin Nile tilapia collagen

\begin{tabular}{|c|c|c|}
\hline Sample & $\mathrm{WAC}(\mathrm{ml} / \mathrm{g})$ & $\mathrm{OAC}(\mathrm{ml} / \mathrm{g})$ \\
\hline Acid-soluble collagen (ASC) & $23.92^{\mathrm{a}} \pm 0.39$ & $26.72 \pm 0.09^{a}$ \\
\hline Pepsin soluble collagen (PSC) & $22.72^{b} \pm 0.19$ & $24.51 \pm 0.56^{b}$ \\
\hline
\end{tabular}

Generally speaking, the hydrophobic interactions between the non-polar amino acids of protein molecules as well as the hydrocarbon chains of oil determine the OAC of the protein [51]. Additionally, [52] reported that the protein with higher OAC gave better shape retention in foods, affect the food flavor and also are important in the functional characteristics of ingredients used in the processing of confectionery and meat industries. These results indicated that ASC and PSC showed higher OAC than WAC. So the hydrophobic groups' content of 
collagen was higher than the hydrophobic groups' content. Therefore, the collagens of Nile tilapia skin could be applied in the meat products.

\subsubsection{Emulsifying Properties}

Emulsifying properties play an essential role in food products, subsequently; they contribute directly to the texture and sensory properties of food [53]. Emulsification is an important property of protein; It includes the emulsify activity and emulsify stability. Emulsifying ability is the function that protein elevates oil and water mixture and then forms the emulsion [20]. The significant difference was found between emulsify activity of ASC and PSC (Table 4) and they were 51.50\% and $54.25 \%$, respectively. Similar to pigskin collagen polypeptides $53.4 \%$ [10] and higher than pacific whiting skin $45.9 \%$ [54] and it is lower than ASC and PSC from fish skin Amiurus nebulosus. They were $64.44 \%$ and $76.19 \%$ respectively [20], whereas Yak bone polypeptides were $57.3 \%$ [10].

Emulsify stability is the capacity that protein keeps oilwater and not separation as well as the resistance strain of external conditions [20].ASC and PSC had similar emulsify ability and emulsify stability (Table 4). Also, emulsify stability can be used as emulsifier in food products. As the importance of emulsifying properties and foaming in the food industry, this result suggests that the collagens of Nile tilapia skin may be used for baking, beverages, and meat products.

Table 4: Emulsifying activity EA (\%) and stability ES (\%) of ASC and PSC

\begin{tabular}{|c|c|c|}
\hline sample & Emulsifying activity EA (\%) & $\begin{array}{c}\text { Emulsifying stability } \\
\text { ES }(\%)\end{array}$ \\
\hline Acid-soluble collagen (ASC) & $51.50^{\mathrm{s}} \pm 0.70$ & $57.92^{\mathrm{a}} \pm 0.11$ \\
\hline $\begin{array}{l}\text { Pepsin soluble collagen } \\
\text { (PSC) }\end{array}$ & $54.25^{b} \pm 0.74$ & $57.615^{\mathrm{a}} \pm 0.54$ \\
\hline
\end{tabular}

\subsubsection{Foaming properties:}

ASC exhibited a higher FA and much stronger FS than that PSC (Figure 7). This result is higher than FA of ASC (14\%) and PSC (4\%) extracted from Amiurus nebulosus Skin [20], and it's similar to the ASC and PSC of red stingray skin collagen 146.67 and $151.67 \%$ respectively Chen et al., 2019[43] and collagen polypeptides of Yak bone and pigskin $163 \%$ and $160 \%$ respectively[10].

Generally speaking, when the protein included more large size peptides, it maybe improves the configuration of a stable film around the gas bubbles [52]. Also, the interaction between water and protein important for foaming was stronger and the hydrophobic areas on the peptide chain are responsible for giving protein its emulsifying and foaming properties [55].

As a result of this foaming property, Nile tilapia skin collagen is applied in food processing as a foaming agent.
On the other hand, foaming properties is an important attribute in food products such as desserts, baked products. [53].

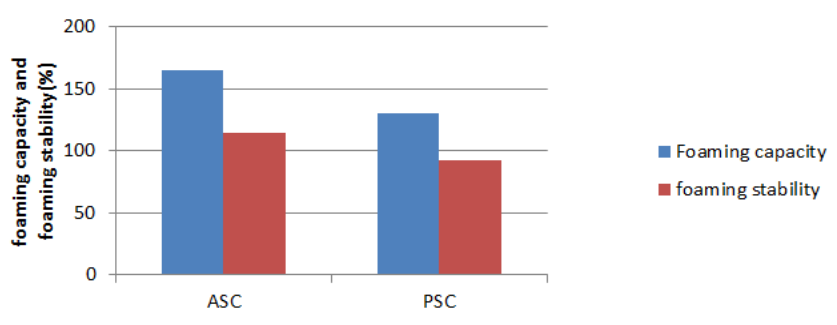

Figure 7: Foaming capacity and foaming stability of acidsoluble collagen (ASC) and pepsin-soluble collagen (PSC) from Nile tilapia skin.

\subsubsection{Gelation properties:}

The effective concentration of collagen on gelation capacity is showed in (Table 5) by taking the least gelation concentration (LGC) as the index of gelation capacity. Lower LGC of Both ASC and PSC collagens were 4\%.usually, lower LGC means better gelation capacity. Hence increasing the protein concentration required to form a stable gel. On the other hand, [56] reported that the balance between hydrophobic interaction and repulsive electrostatic interaction control gel appearance and the gelation mechanism. Generally, Gelation occurs when native globular collagen proteins are denatured in the presence of heat [57]. Therefore, Protein gelation is imperative for the acceptability and preparation of food products.

Table:5 Gelation properties of ASC and PSC from the skin of Nile tilapia

\begin{tabular}{ccc}
\hline Concentration (\%) & ASC & PSC \\
\hline 1 & - & - \\
2 & \pm & \pm \\
3 & \pm & \pm \\
4 & + & + \\
\hline- , Not gelled; \pm , gelled slightly; + , gelled & &
\end{tabular}

\section{Conclusion:}

Collagen from Nile tilapia skin was successfully extracted by ASC and PSC methods. The yield of ASC was higher than PSC. The results obtained show that ASC and PSC have a typical type I collagen characteristics. Both ASC and PSC have a triple-helical structure characteristic. The denaturation temperature (Td) of PSC was slightly lower than that of ASC.ASC and PSC have good functional properties because there were high oil absorption capacity, $26.72 \mathrm{~mL} / \mathrm{g}$ and $24.51 \mathrm{~mL} / \mathrm{g}$, respectively. Both ASC and PSC had excellent foam ability (165.5 and $130.5 \%$, respectively) and foam stability (114.5 and $92.5 \%$, respectively). ASC was better in water and oil absorption capacity and foaming ability than PSC, The Maximum solubility was in $0.5 \mathrm{M}$ acetic acid for ASC and PSC at $\mathrm{pH} 3$ and 2.5 respectively. ASC and PSC have good gelation properties, taking the least 
gelation concentration at $4 \%$ for ASC and PSC. It could be concluded that the characteristics and functional properties of the isolated ASC and PSC indicate that Nile tilapia skin had a good yield of collagen and it could be served as a new source of collagen for food products.

\section{Acknowledgment}

The authors are thankful to the Faculty of Agriculture Minia University for the permission to publish the paper. The assistance rendered by the technical staff of the Food Science Department is greatly appreciated.

\section{References}

[1] Sinthusamran S, Benjakul S, Kishimura H.Comparative study on molecular characteristics of acid soluble collagens from skin and swim bladder of seabass (Lates calcarifer). Food Chem. 2013; 138: 2435-2441.

[2] Hashim P, MohdRidzwan M S, Bakar J, Mat H D. Collagen in food and beverage industries. International Food Research Journal.2015; 22(1): 1 - 8.

[3] Jongjareonrak A, Benjakul S, Visessanguan W, Nagai T, Tanaka M. Isolation and characterisation of acid and pepsin-solubilised collagens from the skin of BrownstripeRed snapper (Lutjanus vita). Food Chemistry.2005; 93(3): 475-484.

[4] Ata STW, Yulianty R, Sami EJ, Ramli N. (2016). Collagen isolation from the skin and bones of skipjack fish (Katsuwonus pelamis). J of Pharm Med Sci.2016; 1(1): 27-30.

[5] Coppola T, Oliviero M, Vitale GA, Lauritano D, Ambra C, Iannace S, Donatella de Pascale, et al. Marine Collagen from Alternative and Sustainable Sources: Extraction, Processing and Applications. Mar. Drugs 2020; 18[4]: 214. [6] Zeng S, Zhang C, Lin H, Yang P, Hong P, Jiang, Z, et al. Isolation and characterisation of acid solubilised collagen from the skin of Nile tilapia (Oreochromis niloticus). Food Chemistry.2009; 116(4):879-883.

[7]GAFRD. Fish statistics year book.2016.

[8] Harati JB, Droval AA, Marques LLM, Fuchs RHB, Cardoso FAR. Evaluation of the Functional and Structural Properties of collagen extracted from Tilapia co-product. J food SciNutr2020; 6: 056.

[9] Gomez-Guillen MC, Gimenez B, Lopez-Caballero M E, Montero M P. (2011). Functional and bioactive properties of collagen and gelatin from alternative sources: A review. Food Hydrocolloids. 25: 1813-1827.

[10] Li Fa, Dongying J, Kai Y. Amino acid composition and functional properties of collagen polypeptide from Yak (Bos grunniens) bone. Food Science and Technology 2009;42: 945-949.

[11] Nagai T, N Suzuki. Isolation of collagen from fish waste material - skin, bone and fins. Food Chem. . 2000; 68: 277-281.

[12] Hukmi NMM, Sarbon NM. Isolation and characterization of acid soluble collagen (ASC) and pepsin soluble collagen (PSC) extracted from silver catfish (Pangasius sp.) skin. International Food Research Journal.2018; 25(5), 17851791 .

[13] Wang J, Pei X, Liu H, Zhou D. Extraction and characterization of acidsoluble and pepsin soluble collagen from skin of loach (Misgurnus anguillicaudatus). International Journal of Biological Macromolecules.2018; 106:544-550.

[14] Ishida Y, Fujita T, Asai K. New detection and separation method for amino acid by high performance liquid chromatography. J. Chromatogr.1981; 204: 143-148.

[15] Singh P, Benjakul S, Maqsood S, Kishimura $H$. Isolation and characterization of collagen extracted from the skin of striped catfish (Pangasianodon hypophthalmus). Food Chemistry.2011; 124: 97-105.

[16] Laemmli U K. Cleavage of structural proteins during the assembly of the head of bacteriophage T4. nature, 1970; 227: 680-685.

[17] Pati F, Adhikari B, Dhara S. Isolation and characterization of fish scale collagen of higher thermal stability, Bioresour. Technol.2010; 101:3737-3742.

[18] Kiew PL, Don MM. The influence of Acetic Acid Concentration on the Extractability of Collagen from the Skin of Hybrid Clarias sp. And Its Physicochemical Properties: A Preliminary Study. Focusing on Modern Food Industry. 2013; (3): 123-128.

[19] Lowry O H, Rosebrough N J, Farr A L, Randall R J. Protein measurement with Folin phenol reagent. Journal of Biological Chemistry.1951; 193: 256-275.

[20] Chen L, Zhao L, Yuan M, Liu H. Function Properties of Collagen from the Skin of Amiurus nebulosus. Journal of Biobased Materials and Bioenergy .2013; 7: 444-448.

[21] Liu D. C, Zhang L W, Hu X H. The functional properties of soybean protein products rich in selenium. China Oils, 1994; 19 (3): 3-7 (in Chinese).
[22] Neto V Q, Narain N, Silva J B, Bora P S. (2001). Functional properties of raw and heat processed cashew nut (Anacardium occidentale, 1.) kernel protein isolates. Nahrung-Food.2001; 45 (4): 258- 262.

[23] Shahidi F, Han X. Q, Synowiecki J. Production and characteristics of protein hydrolysates from capelin (Mallotus villosus). Food Chemistry.1995; 53:285-293.

[24] Coffman C W, Garcia VV. Functional properties and amino acid content of protein isolate from mung bean flour. Journal of Food Technology.1977; 12: 473-484.

[25] SAS. (2003). SAS User's Guide: Statistics. SAS Institute. Cary, NC.

[26] Hamdan F S, Sarbon N M. Isolation and characterisation of collagen from fringe scalesardinella (Sardinella fimbriata) waste materials. International Food Research Journal.2019; 26(1): 133 - 140.

[27] Yao P, Wang H, Wang H, Li Y, Wang M, Zhang H et al. Biochemical and physiological characterization of collagen from the skin of bighead carp (Aristichthysnobilis). Journal of Food, Agriculture and Environment 2012; 10(3\&4): 92-98

[28] VeerurajA, Arumugam M, Ajithkumar T, Balasubramanian T. Isolation and characterisation of collagen from the outer skin of squid (Doryteuthis singhalensis). Food Hydrocolloids 2014; 43: 708-716

[29] Abdollahi M, Rezaei M, Jafarpour A, Undeland I. Sequential extraction of gel-forming proteins, collagen and collagen hydrolysate from gutted silver carp (Hypophthalmichthys molitrix), a biorefinery approach. Food Chem.2018; 242: 568-578.

[30] Song W, Liu D, Sun L, Li B, Hu H. Physicochemical and Biocompatibility Properties of Type I Collagen from the Skin of Nile Tilapia (Oreochromis niloticus) for Biomedical Applications. Mar. Drugs 2019; 17; 137.

[31] Sun L, Hou H, Li B, Zhang, Y. Characterization of acid- and pepsinsoluble collagen extracted from the skin of Nile tilapia (Oreochromis niloticus). Int. J. Biol. Macromol.2017; 99: 8-14.

[32] Zaelani B, Safithri M, Tarman K. ISetyaningsihand M. Collagen isolation with acid soluble method from the skin of Red Snapper (lutjanus sp.).Earth and Environmental Science. 2019; 241.

[33] Liu HY, Li D, Guo S D. Studies on collagen from the skin of channel catfish (Ictaluruspunctaus). Food Chem.2007; 101: 621-625.

[34] Iswariya S,Velswamy P, Uma T S. Isolation and Characterization of Biocompatible Collagen from the Skin of Puffer Fish (Lagocephalusinermis). J Polym Environ2018; 26:2086-2095.

[35] Nagai T, Suzuki N, Tanoue Y, Kai N, Nagashima T. (2010). Characterization of Acid-Soluble Collagen from Skins of Surf Smelt (Hypomesuspretiosus japonicas Brevoort). Food and Nutrition Sciences.2010; 1: 59-66.

[36] Duan R, Zhang J, Dua X,Yao X, Konno K. Properties of collagen from skin, scale and bone of carp (cyprinus carpio). Food Chemstry.2009; 112(3): 702-706.

[37] Wu X, Cai L, Cao A, Wang Y, Li T, Li J. Comparative study on acidsoluble and pepsin-soluble collagens from skin and swim bladder of grass carp (Ctenopharyngodon idella). J. Sci. Food Agric.2016; 96(3): 815-821.

[38] Minh Thuy L T, Okazaki E, Osako K. Isolation and characterization of acid-soluble collagen from the scales of marine fishes from Japan and Vietnam. Food Chem.2014;149: 264-270.

[39] Tan Y, Chang S KC. Isolation and characterization of collagen extracted from channel catfish (Ictalurus punctatus) skin. Food Chem.2018; 242: $147-$ 155

[40] Liu D, Liang L,Regenstein J, Zhou P. Extraction and characterisation of pepsin-solubilised collagen from fins, scales, skins, bones and swim bladders of bighead carp (Hypophthalmichthys nobilis). Food Chemistry.2012; 133:14411448 .

[41] Zeng S, Yin J, Yang S, Zhang C, Yang P, Wu W. (2012).Structure and characteristics of acid and pepsin-solubilized collagens from the skin of cobia (Rachycentron canadum). Food Chemistry.2012; 135:1975-1984.

[42] Sujithra S, Kiruthiga N, Prabhu MJ, Kumeresan R. Isolation and determination of Type I collagen from Tilapia (Oreochromis niloticus) waste International Journal of Engineering and Technology.2013; 5: 0975-4024.

[43] Chen J , Li J ,Li Z, Yi Z, Shi S, Wu K, Li Y, Wu S, et al. Physicochemical and Functional Properties of Type I Collagens in Red Stingray (Dasyatis akajei) Skin. Mar. Drugs.2019; 17, 558.

[44] Zhao WH, Chi CF, Zhao YQ, Wang B. Preparation physicochemical and antioxidant properties of acid-and pepsin-soluble collagens from the swim bladders of miiuy croaker (Miichthys miiuy). Mar. Drugs.2018; 16: 61.

[45] Wang SS, Yu Y, Sun Y, Liu N, Zhou DQ. Comparison of physicochemical characteristics and fibril formation ability of collagens extracted from the skin of farmed river pufer (Takifugu obscurus) and tiger pufer (Takifugu rubripes). Mar. drugs.2019; 17: 462.

[46] Li ZR, Wang B, Chi CF, Zhang QH, Gong YD, Tang JJ, Luo HY, Ding GF. Isolation and characterization of acid soluble collagens and pepsin soluble collagens from the skin and bone of Spanish mackerel (Scomberomorous niphonius). Food Hydrocoll.2013; 31: 103-113. 
[47] Kirti , Khora SS. Isolation and Characterization of Collagens extracted from the Skin of Pufferfish, Lagocephalus wheeleri. Research Journal of Pharmaceutical, Biological and Chemical Sciences.2015; 0975-8585.

[48] Chen J, Li L, Yi R, Xu N, Gao R, Hong B. Extraction and characterization of acid-soluble collagen from scales and skin of tilapia (Oreochromis niloticus). LWT-Food Sci. Technol.2016;66:453-459.

[49]Damodaran S. Amino acids, peptides, and proteins. In: O. R. Fennema (Ed.), Food Chemistry.1996;321-429.

[50] Kinsella J E. (1976). Functional properties of proteins in foods: a survey. Critical Reviews in Food Science \& Nutrition.1976; 7: 219-280.

[51] Jitngarmkusol S,,Hongsuwankul J, Tananuwong K. Chemical compositions functional properties and microstructure of defatted macadamia flours. Food Chem.2008; 110, 23-30.

[52] Souissi N, Bougatef A, Triki-Ellouz Y, Nasri M. Biochemical and functional properties of Sardinella (Sardinella aurita) by-product hydrolysates. Food Technology and Biotechnology.2007; 45(2), 187-194.

[53] Anzani C, Álvarez C, Mullen A. Assessing the effect of Maillard reaction with dextran on the techno-functional properties of collagen-based peptides obtained from bovine hides. Food Science and Technology.2019;(19)31142-9.

[54] Kim J S, Park J W. Partially Purified Collagen from Refiner Discharge of Pacific Whiting Surimi Processing. Journal of Food Science.2005; 70(8): 511516.

[55] Cole CGB. Gelatin. In: Francis FJ (ed) Encyclopedia of food science and technology.2000; 2, 2nd edn. Wiley, New York, pp 1183-1188.

[56] Egeandsal, B. Heat induced gelling in solutions of ovalbumin. Journal of Food Science.1980; 45: 570-573.

[57] Shon Ji-H E, Su J H, Jong-Bang E. Effect of Processing Conditions on Functional Properties of Collagen Powder from Skate (Raja kenojei) Skins. Food Sci. Biotechnol.2011; 20(1): 99-106. 